\title{
AGGRESSIVE FIBROMATOSIS OF BREAST: A RARE CASE REPORT
}

Vikrant Sharma1, Nityasha Daral ${ }^{2}$, Amit Singla ${ }^{3}$, Deepanshu Gupta ${ }^{4}$, Rajshree Seth ${ }^{5}$

\section{HOW TO CITE THIS ARTICLE:}

Vikrant Sharma, Nityasha Daral, Amit Singla, Deepanshu Gupta, Rajshree Seth. "Aggressive Fibromatosis of Breast: A Rare Case Report". Journal of Evolution of Medical and Dental Sciences 2014; Vol. 3, Issue 13,

March 31; Page: 3295-3298, DOI: 10.14260/jemds/2014/2283

ABSTRACT: Fibromatosis, a locally aggressive but non-metastasizing neoplastic proliferation of fibroblastic cells, commonly encountered in the abdominal wall and extra-abdominal sites but rarely occurs in the breast. Here we report a case of aggressive fibromatosis of breast, which presented as a palpable mass in the right breast of a 53-year-old female. The physical examination revealed a $12 \times 10$ $\mathrm{cm}$ sized ovoid mass in the right upper outer quadrant. Ultrasonogram demonstrated an $8 \times 5 \mathrm{~cm}$ sized hypoechoic mass with peripheral increased vascularity on doppler imaging. Wide local excision was done and pathology revealed aggressive fibromatosis.

KEYWORDS: Aggressive fibromatosis, non-metastasizing, fibroblastic cells, wide local excision.

INTRODUCTION: Aggressive fibromatosis is a rare, locally aggressive disease. By definition, fibromatosis is non-encapsulated well-differentiated fibroblastic lesion composed of relatively uniform fibroblasts and collagen and forming a firm, solitary, or multinodular mass with an infiltrative growth pattern.1,2 Aggressive fibromatosis is a commonly encountered entity in the abdominal wall and at extra abdominal site but very rare in breast and the incidence of mammary fibromatosis is less than $0.2 \%$ of primary breast neoplasm.1,3 The etiology is unknown, but an association with Gardner's syndrome has been described. Clinical and imaging findings may simulate breast carcinoma.

CASE REPORT: 53 year old lady presented in surgical outpatient department with recurrent right breast lump of one month duration. She had undergone excision of a similar lump about 3 months back by a private practitioner. The lump was localized in the upper outer quadrant of the breast and was associated with occasional mild pain. Examination of the right breast revealed a mass in the upper outer quadrant measuring $12 \times 10 \mathrm{~cm}$, hard in consistency, mobile, slight tender to touch and not attached to the skin or any underlying structure. The nipple, areola and breast skin were normal. Also a linear scar mark of size $7 \mathrm{~cm}$ was present about $4 \mathrm{~cm}$ from the nipple on right breast s/o prior excision biopsy. The left breast and both axilla were normal. Bilateral so no mammogram was done which showed a well-defined opacity with no irregularity or micro calcification with increased parenchymal density measuring 8x5 centimeters in the lateral aspect of the right breast (fig 1). No focal abnormality was noted in the left breast. No axillary lymphadenopathy seen bilaterally. ACR 


\section{CASE REPORT}

\section{BIRADS: 3}

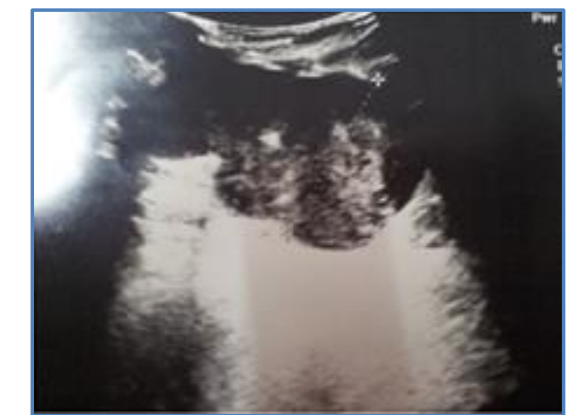

FIG. 1: SHOWING SONOMAMMOGRM OF RIGHT BREAST

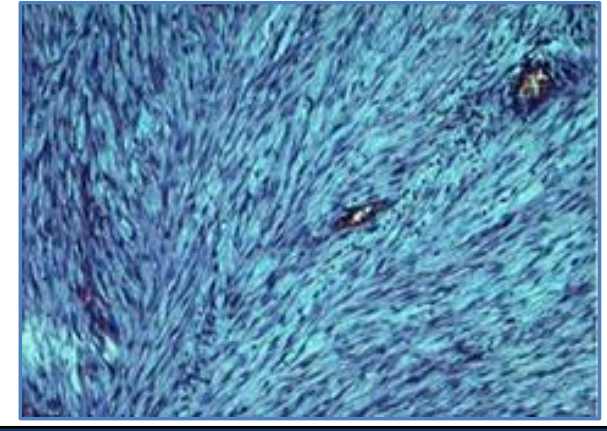

FIG. 2: SECTION SHOWING STROMAL PROLIFERATION WITH PLEOMORPHIC STROMAL CELLS BREAST

FNAC from right breast lump was done which showed large no. of hypercellular stromal fragments with singly dispersed and groups of spindle cells in metachromatic stroma leading to cytological findings suggesting PHYLLOIDES tumor. Wide local excision was carried out considering the size and recurrence of tumor.

On gross histopathological examination, tumor showed stromal proliferation with pleomorphic stromal cells and it was infiltrating into surrounding adipose tissue (fig. 2). Sections reviewed after extensive sampling and immunohistochemistry showed positivity to SMA, EMA (positive in entrapped gland), and negativity for desmin.

Also tumor showed infiltrating edge with entrapment of adjoining breast parenchyma and closest resected margin. Thus the histological features favored the final diagnosis of aggressive fibromatosis over inflammatory myofibroblastic tumor. As tumor showed infiltration in closest resected margin patient underwent simple mastectomy and resected base, skin, nipple and areola were negative for tumor.

DISCUSSION: Breast fibromatosis is a very rare mesenchymal neoplasm (cell growth) which may occur in women, typically between the ages of 25 and 45. It is one of a group of benign 'spindle-cell' proliferative lesions which are often difficult to distinguish from malignant breast cancer, especially spindle cell carcinoma. It is important to recognize mammary fibromatosis as it presents a big dilemma for the clinician, because it mimics cancer clinically, radiologically and sometimes cytologically. ${ }^{2}$ Although the exact pathogenesis of mammary fibromatosis is not clear, at least $30 \%$ of patients recount history of significant trauma to the involved area. ${ }^{2,4}$ Antecedent trauma has been described at the site of fibromatosis in some patients and in association with saline-filled breast implants. ${ }^{2,5,6}$ Few cases have been associated with Gardner's Syndrome; familial multi centric fibromatosis and familial adenomatous polyposis which suggests a genetic predisposition and probably alteration of the APC/ beta-catenin pathway.1,2, 4, 5, 7

Patients with mammary fibromatosis almost always present with a painless palpable, firm or hard tumor that suggests carcinoma on clinical examination as the case with our patient. Skin dimpling and retraction are relatively common signs of breast fibromatosis that is likely to reinforce the clinical impression of carcinoma. ${ }^{2}$ Mammography reveals a stellate tumor indistinguishable from carcinoma. The presence of mammographically detectable microcalcifications; however, favors the diagnosis of carcinoma since calcifications are unusual in mammary fibromatosis. 
Rarely, the tumor is non-palpable and detected initially by mammography. ${ }^{2}$ Pre-operative diagnosis of fibromatosis by FNAC is rare. Nevertheless, fine needle aspiration cytology, although not entirely specific, may be a source of important information in patients with breast fibromatosis. In particular, it confidently allows the exclusion of breast cancer and other more common diseases and is useful in planning a surgical approach to the lesion. ${ }^{8}$

This illustrates the importance of the triple approach (clinical, radiological and cytological input), in the management of breast disease. ${ }^{9,10}$ Histologically, fibromatosis is composed of uniform, spindle shaped fibroblasts forming sweeping or interlacing fascicles entrapping ducts and lobules with an infiltrative edge. The degree of cellularity varies, ranging from relatively cellular to predominantly collagenized lesions.

Devouassoux-Shisheboran et al studied the morphofunctional features of 33 cases of fibromatosis and showed that the cellularity of the lesion varied with the patient's age. ${ }^{11}$ Lesions in the younger patients (childbearing age) were significantly more cellular than those of the perimenopausal and postmenopausal groups, it displayed larger proportion of cells with mild atypia and were mitotically more active.

Compared to lesions in the childbearing group lesions in the perimenopausal and postmenopausal patients were significantly more fibrous and presented with prominent inflammatory cells. Numerous reports showed that even though extramammary fibromatosis usually exhibit positivity for ER and PR, mammary fibromatosis is consistently devoid of such receptors. ${ }^{2,8,12}$ moreover, Devouassoux-Shisheboran et al have shown that cytoplasmic pS2 protein expression, which is induced by estrogen, is consistently negative in their series of 33 cases.

Therefore, no benefit from anti-estrogen therapy would be expected in mammary fibromatosis. One caveat to this would be that tamoxifen has been shown to induce synthesis of transforming growth factor beta 1 by ER-negative fibroblasts, which may explain the effectiveness of tamoxifen on ER negative fibromatosis. ${ }^{11}$

Because of the consistent absence of ER and PR receptors in mammary fibromatosis, a positive reaction for either receptor in a spindle cell neoplasm of the breast would help exclude fibromatosis from the differential diagnostic consideration for practical purposes. Along the same lines, since myofibroblastoma of the breast was found to express AR, AR positivity in a well delineated myofibroblastic proliferation of the breast would favor the diagnosis of myofibroblastoma over that of fibromatosis. ${ }^{11}$

This case shows positivity for smooth muscle actin and EMA and negativity for desmin and both estrogen and progesterone receptors, hence being consistent with the findings in the literature. Wide local excision is the recommended treatment, because of the stellate configurations and grossly inapparent extensions of most lesions. Negative margins are particularly important in fibromatosis as there are no other treatment modalities. ${ }^{3}$

As breast fibromatosis do not demonstrate metastatic capabilities, axillary dissection is not performed. ${ }^{4} \mathrm{~A}$ literature review conducted by Trey Thomas et al suggests that patients should undergo quarterly clinical examination for a minimum of three years; as available literature suggests the majority of local recurrences manifest within this time frame.4There is no evidence that postoperative radiotherapy, chemotherapy or hormonal treatment is useful as an adjunct to surgery for primary treatment or to control recurrent disease. ${ }^{2}$ This patient is on regular follow up in the outpatient clinic and is recurrence free at one year. 


\section{REFERENCES:}

1. Wargotz ES, Norris HJ, Austin RM, et al. Fibromatosis of the breast: A Clinical and Pathological Study of 28 cases. Am J Surg Pathol 1987; 11:38- 45.

2. Rosen PP, Emsberger D. Mammary fibromatosis. A benign spindle-cell tumor with significant risk for local recurrence. Cancer 1989; 63: 1363-9.

3. Nakano S, Ohtsuka M, Hasegawa T, et al. Fibromatosis of the Breast: a Case Report. Breast cancer 2002; 9:179-83.

4. Thomas T, Lorino C, John J. Fibromatosis of the breast: A Case Report and Literature Review. J Surg Oncol 1987; 35:70-4.

5. Reis-Filho JS, Milanezi F, Pope LZB, et al. Primary fibromatosis of the Breast in a Patient with Multiple Desmoid Tumors. Report of a Case with Evaluation of Estrogen and Progesterone Receptors. Pathol Res Pract 2001; 197: 775-9.

6. Ng WH, Lee JS, Poh WT, et al. Desmoid tumor (fibromatosis) of the breast. A clinician's dilemma-a case report and review. Arch Surg 1997; 132:444-6.

7. Abraham SC, Reynolds $\mathrm{C}$, Lee JH, et al. Fibromatosis of the Breast and Mutations Involving the APC/ Beta-Catenin Pathway. Human Pathology 2000; 33:39-46.

8. Youssefzadeh S, Salomonowitz E, Reiner A, et al. Subsequent Bilateral Occurrence of Fibrous Breast Tumors; A Case Report. European Journal of Radiology 1990; 11:218-21

9. Chhieng DC, Cohen JM. Fine Needle Aspiration (FNA) Cytology of Mammary Fibromatosis: A Case Report and Review of Literature. Cytopathoplogy 1999; 10:354-9.

10. Rusell RCG, Williams NS, Bulstrode CJK. Bailey \& Love's Short Practice of Surgery. 23rdedn. London: Arnold, 2000:750-1.

11. Devouassoux-Shisheboran M, Schammel MD, Man YG, et al. Fibromatosis of the breast: agecorrelated morphofunctional features of 33 cases. Arch Pathol Lab Med 2000; 124:276-80.

12. Magro G, Michal M, Bisceglia M. Benign spindle cell tumors of the mammary stroma: diagnostic criteria, classification, and histogenesis. Pathol Res Pract 2001; 197: 453-66.

\section{AUTHORS:}

1. Vikrant Sharma

2. Nityasha Daral

3. Amit Singla

4. Deepanshu Gupta

5. Rajshree Seth

\section{PARTICULARS OF CONTRIBUTORS:}

1. Senior Resident, Department of Surgery, SMS, Jaipur, PGIMS Rohtak.

2. Associate Professor, Department of Surgery, PGIMS Rohtak.

3. Senior Resident, Department of Surgery, ESI Ludhiana.

4. $3^{\text {rd }}$ Year Post Graduate, Department of Surgery, PGIMS Rohtak.
5. $3^{\text {rd }}$ Year Post Graduate, Department of Surgery, MGMS Jaipur.

\section{NAME ADDRESS EMAIL ID OF THE CORRESPONDING AUTHOR:}

Dr. Vikrant Sharma, C-96, FF, Kirti Nagar, New-Delhi-110015.

E-mail: vikrant_doc@yahoo.com

Date of Submission: 27/02/2014.

Date of Peer Review: 28/02/2014.

Date of Acceptance: 10/03/2014.

Date of Publishing: 25/03/2014. 